\title{
Translation of regenerative technologies into clinical paradigms
}

Atta Behfar, Ruben Crespo-Diaz, Andre Terzic and Bernard J. Gersh

We thank Shigeo Masuda et al. for their Correspondence (Emerging innovation towards safety in the clinical application of ESCs and iPCs. Nat. Rev. Cardiol. doi:10.1038/nrcardio.2014.9-c1 $)^{1}$ on our Review (Cell therapy for cardiac repairlessons from clinical trials. Nat. Rev. Cardiol. 11, 232-246; 2014). ${ }^{2}$ Regenerative therapies in cardiovascular medicine are disruptive technologies that might lead to definitive solutions for patients with progressive heart disease, who have limited treatment options. The emerging regenerative medicine algorithm is poised to radically transform patient management, and curb escalating health-care costs. ${ }^{3}$ Stem-cell therapy for acute or chronic heart disease exemplifies the promise of regenerative medicine, and has largely been applied in the clinical-trial setting to complement current standards-of-care. ${ }^{2}$ In trials of patient or donor-derived adult stem cells, adverse events are continually monitored because any new technology might include unconsidered risks associated with clinical application. This evaluation has established a remarkable safety profile of diverse adult progenitor cell types and modes of delivery, albeit with potential for the development of arrhythmias reported in initial trials using myoblasts. ${ }^{4,5}$ 'Next-generation' approaches build on this demonstrated safety and feasibility record, while integrating methods, such as organ conditioning, cell selection, or lineage specification, to optimize and augment the therapeutic effect on the ailing heart. ${ }^{6-9}$

Future regenerative technologies will include both cellular and acellular biotherapies, mandating equally rigorous trial-based scrutiny and long-term safety surveillance. A case-in-point is the anticipated use of pluripotent stem cells. These quintessential stem-cell populations can generate any cell type within the body, and accordingly are thought to possess the greatest regenerative potential. However, their innate regenerative propensity carries a risk of uncontrolled growth that must be tempered before delivery. ${ }^{10}$ For example, pluripotent stem cells can be exposed to signals that induce a cardiac intermediate phenotype committed to a cardiovascular fate and devoid of tri-lineage potency. ${ }^{11}$ An alternative approach is to select a stagespecific embryonic antigen-1-positive population after stimulating embryonic stem cells with bone morphogenetic protein $2 .^{12}$ The risk of residual undifferentiated stem cells within a differentiated progenitor population has also led to the development of targeted approaches that selectively purge contaminating pluripotent stem cells and reduce the risk of uncontrolled cell growth upon transplantation. ${ }^{13}$ The Correspondence from Masuda and colleagues ${ }^{1}$ highlights ongoing advances in this field across the natural and bioengineered pluripotent stem-cell spectrum, at a time when translational experience with these platforms has led to regulatory approval for human studies. ${ }^{14}$

As science-driven discoveries become ready for clinical testing, the health-care community has an important role in tempering the excitement surrounding the potential of these technologies, and highlighting their true improvement to current medical standards. Importantly, biotherapies cannot be assessed in isolation, but instead must be matched to the appropriate patient population and delivered by the most-efficient means. All biologics carry an inherent risk of adverse clinical events. A risk-to-benefit profile for each new technique is, therefore, required to enable understanding, for both patients and clinicians, of the potential value of each new therapy. Our obligation is to develop each new technology with adherence to rigorous safety, feasibility, and efficacy standards, as we translate promising science into durable therapeutic paradigms and manage innovation to optimize outcome. $^{15}$
Centre for Regenerative Medicine and Division of Cardiovascular Diseases, Mayo Clinic, $1001^{\text {st }}$ Street SW, Rochester, MN 55905, USA (A.B., R.C.-D., A.T., B.J.G.).

Correspondence to: A.B.

behfar.atta@mayo.edu

\section{Competing interests}

The authors declare no competing interests

1. Masuda, S. et al. Emerging innovation towards safety in clinical application of ES/iPS cells Nat. Rev. Cardiol. http://dx.doi.org/10.1038/ nrcardio.2014.9-c1.

2. Behfar, A., Crespo-Diaz, R., Terzic, A. \& Gersh, B. J. Cell therapy for cardiac repair -lessons from clinical trials. Nat. Rev. Cardiol. 11, 232-246 (2014).

3. Terzic, A., Harper, C. M. Jr, Gores, G. J. \& Pfenning, M. A. Regenerative medicine blueprint. Stem Cells Dev. 22 (Suppl. 1), 20-24 (2013).

4. Telukuntla, K. S., Suncion, V. Y., Schulman, I. H. \& Hare, J. M. The advancing field of cellbased therapy: insights and lessons from clinical trials. J. Am. Heart Assoc. 2, e000338 (2013).

5. Sanganalmath, S. K. \& Bolli, R. Cell therapy for heart failure: a comprehensive overview of experimental and clinical studies, current challenges, and future directions. Circ. Res. 113, 810-834 (2013).

6. Assmus, B. et al. Effect of shock wavefacilitated intracoronary cell therapy on LVEF in patients with chronic heart failure: the CELLWAVE randomized clinical trial. JAMA 309, 1622-1631 (2013).

7. Malliaras, K. et al. Intracoronary cardiospherederived cells after myocardial infarction: evidence of therapeutic regeneration in the final 1-year results of the CADUCEUS trial (CArdiosphere-Derived aUtologous stem CElls to reverse ventric Ular dySfunction). J. Am. Coll. Cardiol. 63, 110-122 (2014).

8. Bartunek, J. et al. Cardiopoietic stem cell therapy in heart failure: the C-CURE (Cardiopoietic stem Cell therapy in heart failURE) multicenter randomized trial with lineage-specified biologics. J. Am. Coll. Cardiol. 61, 2329-2338 (2013).

9. Terzic, A. \& Behfar, A. Regenerative heart failure therapy headed for optimization. Eur. Heart $J$. 35, 1231-1234 (2014).

10. Lee, A. S., Tang, C., Rao, M. S., Weissman, I. L. $\&$ Wu, J. C. Tumorigenicity as a clinical hurdle for pluripotent stem cell therapies. Nat. Med. 19, 998-1004 (2013).

11. Behfar, A. et al. Cardiopoietic programming of embryonic stem cells for tumor-free heart repair. J. Exp. Med. 204, 405-420 (2007). 


\section{CORRESPONDENCE}

12. Blin, G. et al. A purified population of multipotent cardiovascular progenitors derived from primate pluripotent stem cells engrafts in postmyocardial infarcted nonhuman primates. J. Clin. Invest. 120, 1125-1139 (2010)
13. Smith, A. J. et al. Apoptotic susceptibility to DNA damage of pluripotent stem cells facilitates pharmacologic purging of teratoma risk. Stem Cells Transl. Med. 1, 709-718 (2012).

14. Menasché, P. et al. Towards a clinical use of human embryonic stem cell-derived cardiac progenitors: a translational experience. Eur. Heart J. http://dx.doi.org/10.1093/eurheartj/ehu192.

15. Waldman, S. A. \& Terzic, A. Managing the innovation supply chain to maximize personalized medicine. Clin. Pharmacol. Ther. 95, 113-118 (2014). 